\title{
ADDENDUM
}

\section{Addendum to: Characterization of the resistance to the anorectic and endocrine effects of leptin in obesity-resistant rats fed a high-fat diet. Journal of Endocrinology 2004, 183 289-298}

\author{
G Tulipano, A V Vergoni, D Soldi, E E Muller and D Cocchi
}

The aim of our work was to compare the degree of leptin resistance in diet-induced obesity-prone and resistant rats, both in terms of reduction of feeding and of endocrine effects on somatotroph and thyroid axes. We concluded that both groups of rats show a selective resistance to the anorectic effect of leptin while the pathways mediating the neuroendocrine effects of the peptide were preserved.

In our paper we omitted to acknowledge the study previously published by Levin and Dunn-Meynell (2002), which showed that diet-induced obesity (DIO)-prone rats are less sensitive than diet-resistant animals to the leptin's suppressive effect on food intake as well as on neuropeptide $\mathrm{Y}$ expression in the arcuate nucleus. Differences in the length of the diet period (12 weeks in our paper vs 4 weeks in Levin \& Dunn-Meynell 2002) or in fat concentration of the diet (20\% vs 30\%) may account for the divergent results.

\section{References}

Levin BE \& Dunn-Meynell AA 2002 Reduced central leptin sensitivity in rats with diet-induced obesity. American Journal of Physiology - Regulatory, Integrative and Comparative Physiology 283 R941-R948. 